Int. J. Electrochem. Sci., 14 (2019) 7389 - 7400

\title{
Differential Scanning Calorimetry and Electrochemical Tests for the Analysis of Delamination of 3PE Coatings
}

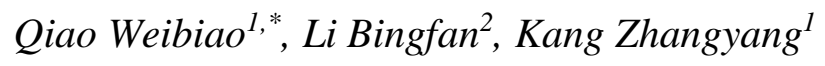 \\ ${ }^{1}$ North China University of Water Resource and Electric Power, China; \\ ${ }^{2}$ China University of Petroleum (East China), China \\ *E-mail: qwb201710@163.com
}

doi: $10.20964 / 2019.08 .05$

Received: 12 October 2018 / Accepted: 27 May 2019 / Published: 30 June 2019

In order to identify the causes of coating delamination on buried pipelines, a field test was conducted to determine the environmental condition of delaminated coatings, and then an electrochemical test and DSC were used to find the cause of delamination. The results show that the main cause of delaminated coatings with defects is the diffusion of electrolyte on the coating and metal interface, which can be divided into three stages, the formation of corrosive crevice, oxygen concentration corrosion, and the hydrogen evolution process. In addition, based on the physical meaning of EECs, the correlation between $f_{\theta \max }$ and all other parameters was established. The result of DCS demonstrates that lacking the crosslinking density of epoxy can also result in delamination of 3PE coatings.

Keywords: 3PE anti-corrosive coating; Delamination; Cathodic protection; Coating/metal interface; Glass transition temperature

\section{FULL TEXT}

(C) 2019 The Authors. Published by ESG (www.electrochemsci.org). This article is an open access article distributed under the terms and conditions of the Creative Commons Attribution license (http://creativecommons.org/licenses/by/4.0/). 